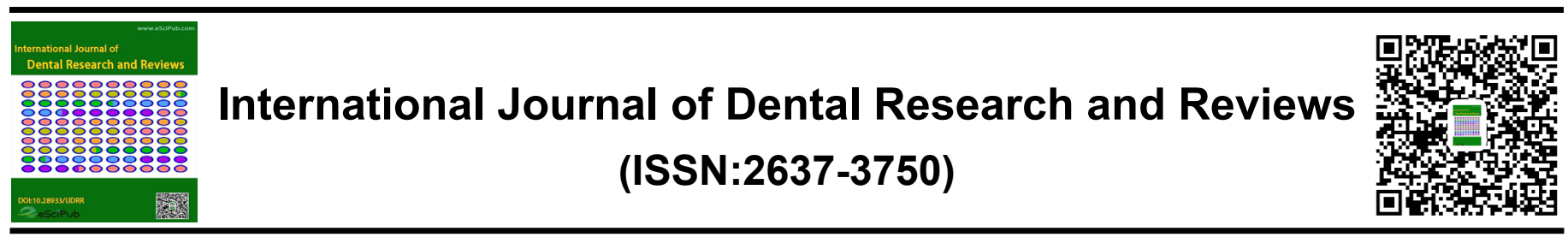

\title{
RAPID PROTOTYPING - A PROSPECTIVE PARADIGM A NARRATIVE REVIEW
}

\section{Naji Alharethi}

Department of Prosthodontics, College of Dentistry in Ar Rass, Qassim University, Ar Rass, Kingdom of Saudi Arabia

\begin{abstract}
Computational modelling signifies the simulation of real life layout in a virtual domain by the transfiguration of physical structures into numerical models, which then is processed into objects. It has restructured the field of Bio - medical engineering in the past 40 years. It has conceptualised the transposition of the visual to the visual-tactile portrayal of anatomical objects leading to a new kind of reciprocity called 'touch to comprehend', paving way for educational approaches. This advent of Rapid prototyping has opened new prospects in medical field, especially dentistry with its accuracy and speed. Rapid prototyping is an additive manufacturing technology that produces prototype models by addition of materials in a layer by layer process. With new researches coming to the fore for molding materials and the forming process of RP techniques, this technology has become trendsetter in dental prosthesis fabrication. This article provides a Narrative review of the evolution and its foray into Prosthodontics through the multiple technological options it has panned.
\end{abstract}

Keywords: Additive Manufacturing, 3D printing, Stereolithography, Rapid Prototyping
*Correspondence to Author:

Dr.Naji Alharethi

Department of Prosthodontics, College of Dentistry in Ar Rass, Qassim University, Ar Rass, Kingdom of Saudi Arabia

How to cite this article:

Naji Alharethi. RAPID PROTOTYPING - A PROSPECTIVE PARADIGM-A NARRATIVE REVIEW. International Journal of Dental Research and Reviews, 2021, 4:49.

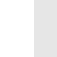

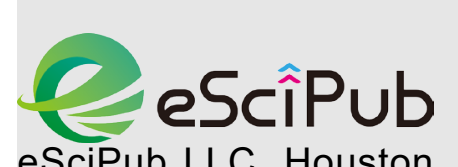

eSciPub LLC, Houston, TX USA. Website: https://escipub.com/ 


\section{INTRODUCTION:}

Over the previous four decades, a furtherance in biomedical field has been due to the advancement of different engineering applications. Dentistry is one such derivative of medicine having a prolonged parody of amalgamating engineering to its patient solutions, especially dental prosthetics. The increasing demand for excellence in diagnosis and treatment of the changes in bucco-maxillofacial complex has become a great challenge. Hitherto, the incorporation of modern technologies in Radiology, Computer aided Technology and devising advanced treatment modalities has assumed an outstanding and foremost strategy in the biotechnology field. Out of those newness is the cutting edge technologyRAPID PROTOTYPING (RP), which uses images from computed tomography (CT) and fabricates three-dimensional virtual models from the CAD (Computer Aided Design) system ${ }^{1,2}$

Rapid prototyping (RP), also referred to as Additive Manufacturing or threedimensional (3D) printing or Solid Free Form Fabrication, is a group of emerging technologies that manufactures $3 \mathrm{D}$ objects in a layer-by-layer aspect from a predefined 3D computer model $2,3,4,5$

The term "Additive Manufacturing" is defined by the American Society for Testing and Materials (ASTM) as: 'the process of joining materials to make objects from 3D model data, usually layer upon layer, as opposed to subtractive manufacturing methodologies'6,7,8. . In prosthodontics, additive manufacturing fabricates a replica pattern in wax or acrylic that can be transformed to a definitive prosthesis in metals, resins, or ceramics. The application of additive manufacturing in dentistry is due to its ability to produce a variety of shapes that conform to any biological site.

Rapid prototyping has caused an archetypical shift from century old conventional methods to a modern less cumbersome methods. The ponderous steps in converting a raw material to a complete assembled, usable product can be phased out by using this process at a fraction of the time originally consumed. ${ }^{8,9}$

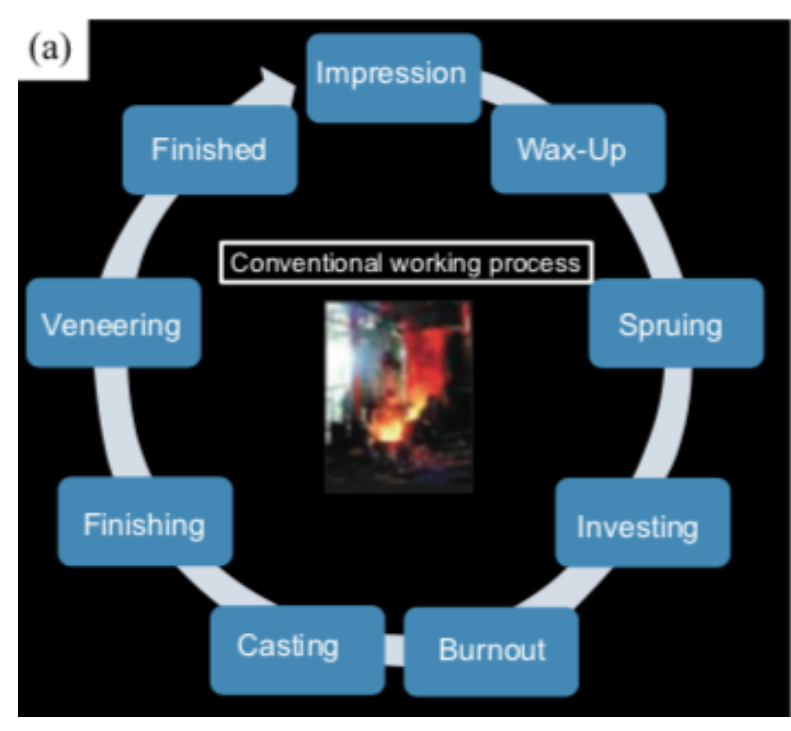

Figure $1 \mathrm{a}$ : Conventional lab Process

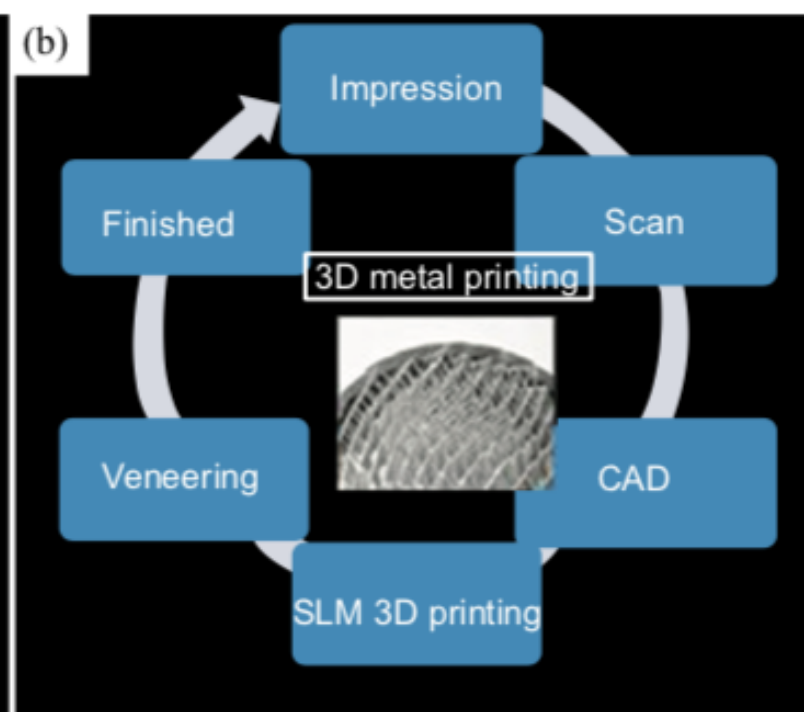

1 b: Rapid Prototyping Process ${ }^{61}$ 


\section{HISTORICAL DEVELOPMENT:}

Prototyping or model making is a timehonoured century old practice. Prototyping processes has egressed through three phases of development corresponding to the transpiring modelling process in computer graphics $^{10,11,12}$.

First Phase:

- Manual Prototyping

- Long established practice preceeding many centuries

- Natural prototyping technique craft based, skill based and labour intensive

- Second Phase:

- Soft or Virtual Prototyping

- Emerged around mid-1970s

- Works with highly complex structures

- Virtual prototype can be simulated and tested like a physical model with exact mechanical and other properties

- Third Phase:

- Rapid Prototyping

- Mid1980s

- Hard prototype fabricates in succint time

- Progressed with advancement in Computer based technology

- Hard prototype can also be used for limited testing

- assist in the manufacturing of the actual product itself and are relatively accurate and faster

\section{Evolutionary History:}

1770 - Mechanisation Earliest forms of Manual Prototyping

1946 - First Computer

1952 - First Numerical Control (NC) Machine Tool

1960 - First commercial Laser

1961 - First commercial Robot
1963 - First interactive graphics system (early version of Computer Aided Design)

1970 - Development of the basic tools of Mathematics describing the 3D aspects, resulting in the earliest theories of Solid Modelling

1987 - Brix and Lambrecht applied first prototype in health care.

1988 - First commercial Rapid Prototyping System

1991 - Human anatomy models produced with stereolithography were first empoyed in a maxillofacial surgery clinic in Vienna. ${ }^{13,14,15}$

RP processes are based on analogous data pre-processing operations which transforms the virtual 3D computer-aided design or 3D scanned models into layered information files necessary for fabrication of 3D objects. These maybe done by four different methods

1. Formative Process

2. Subtractive Process

3. Additive Process

4. Hybrid process

The limitation of Subtractive process of Numerical milling machines such as restricted motion capability, abrasiveness and heat generation, difficulty in programming complex geometries(access to undercuts) and tool/workpiece collisions are major constraints in medical applications. The other constraints are the materials used to fabricate the physical model. These materials utilized should be hard, tough and sterilisable. ${ }^{16}$

\section{STEPS IN RP PROCESS:}

The basic principle of this new RP technology is derived on the replication of three-dimensional computer models into physical forms by piling materials layer by layer as thin sections. 


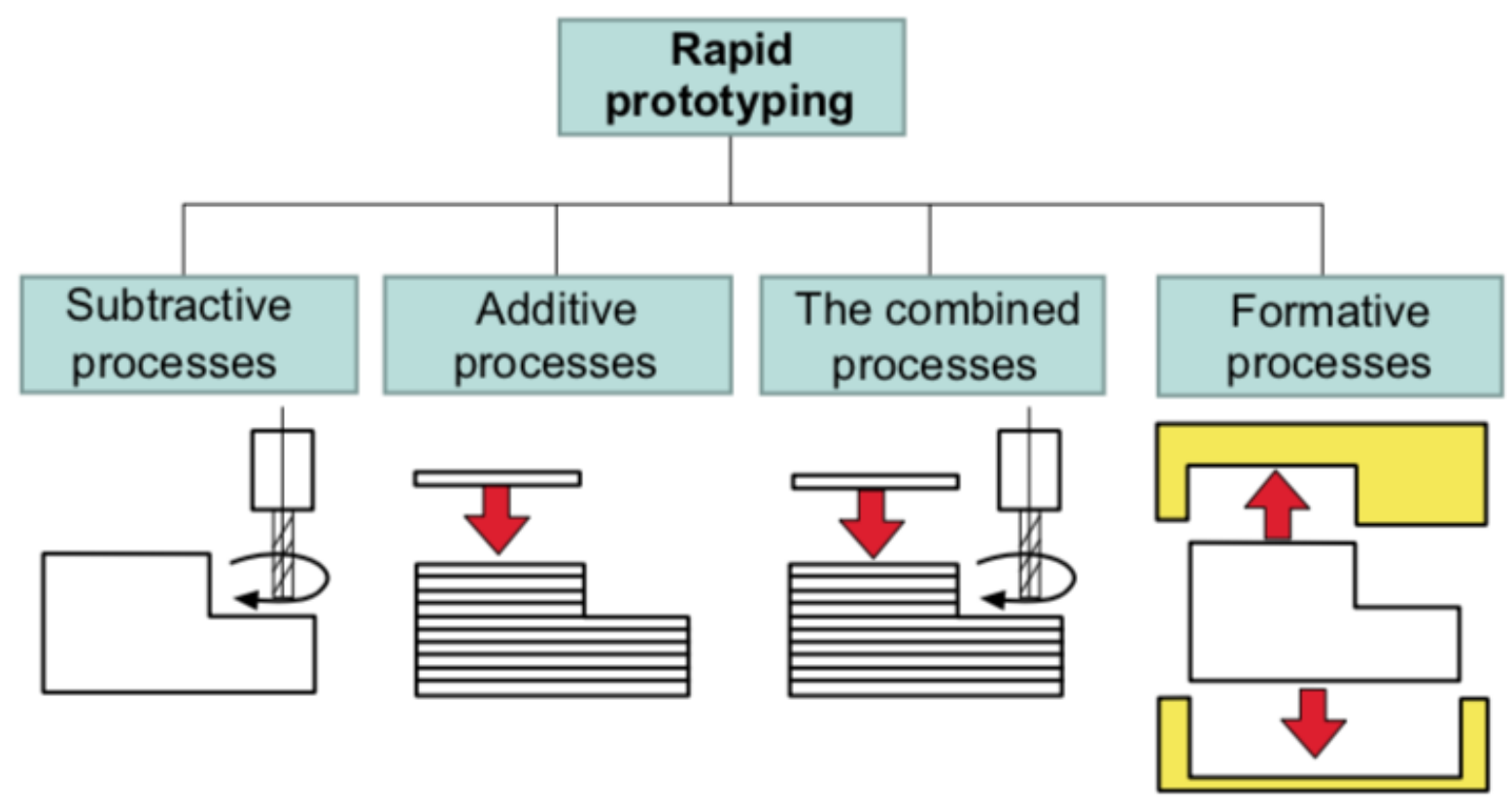

Figure $2^{62}$ : Four fundamental fabrication process

\section{D Printing Process}

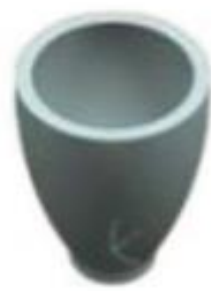

3D Cad Model

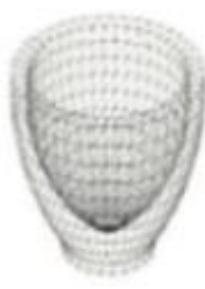

STL

File

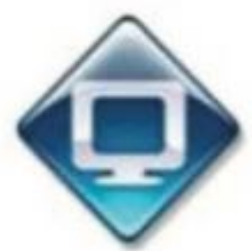

Slicing

Software

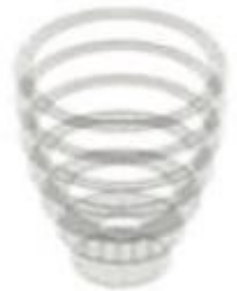

Layer Slices \& Tool Path

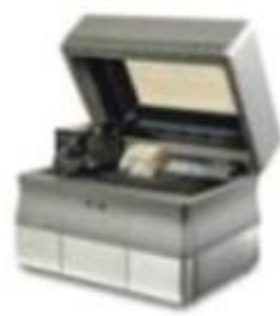

3D

Printer

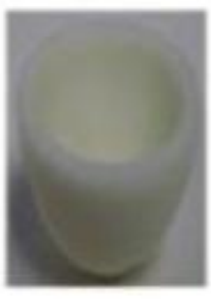

3D

Object

Figure 363: Rapid Prototyping Process

The object to be printed is designed or scanned using Computer assisted technology. It is then fed into the Computer where the Data obtained is converted into STL file. STL (Standard Tessellation Language) is the standard file type used by most or all rapid prototyping systems. A STL is a triangulated representation of a 3D CAD model. The triangulation of a surface will cause faceting of the 3D model. There are many softwares for conversion of the DICOM files into STL file format. Some of them are OnDemand3D, In2Guide,
Easy Riter, Surgical Replica. This file then generates tessellated object description, slicing the layers and finally printing the desired structure.

\section{CLASSIFICATION}

Rapid Prototyping or AM technologies are based on the dispersionaccumulation principle. The material or additive fillers transforms through solidification from its original state of solid, liquid, or powder by successive layers within a predetermined space using electronic processes.

They are classified broadly as ${ }^{17,18}$ 
I. Based on Material Phases

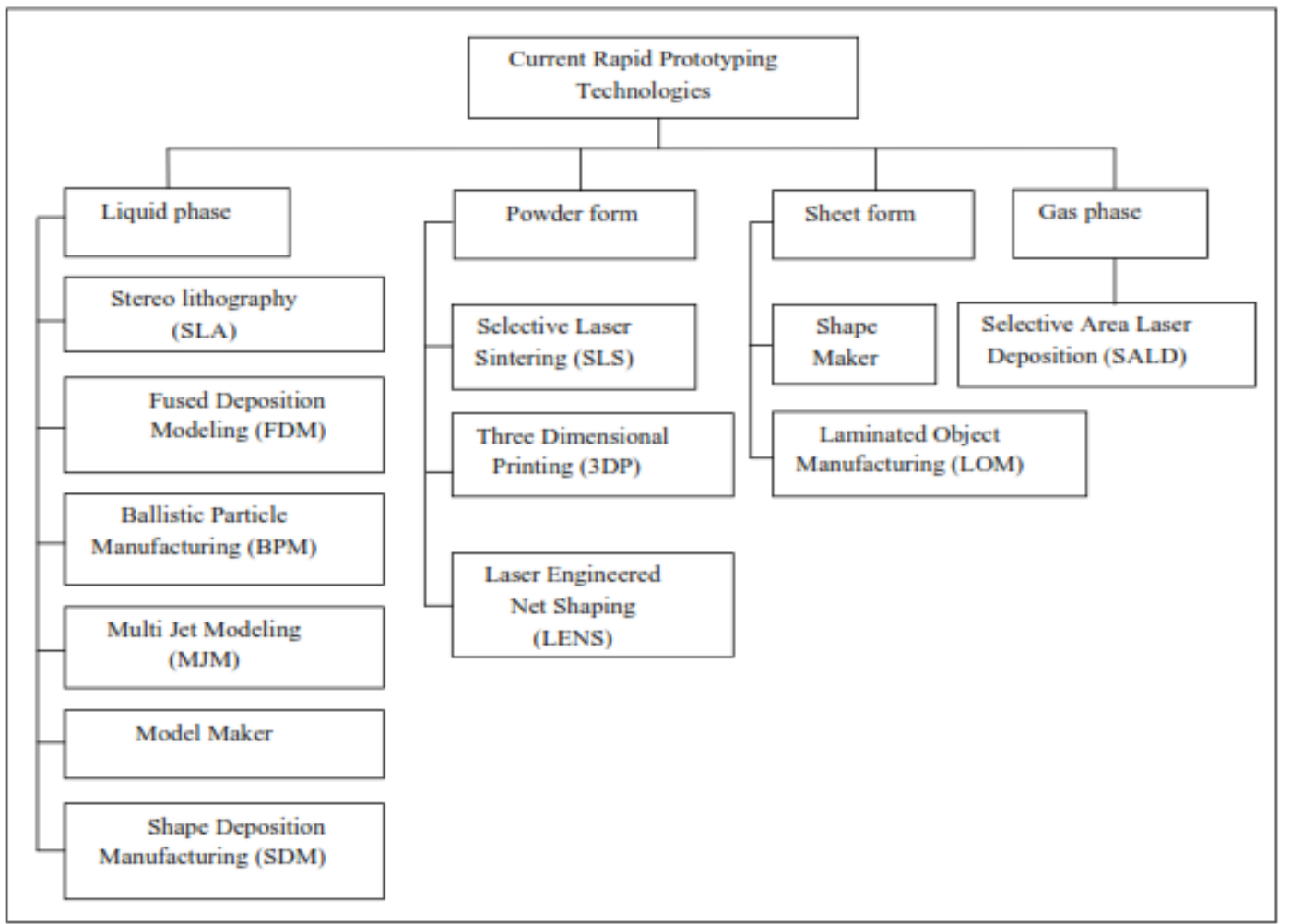

II. Based on Binding Mechanisms

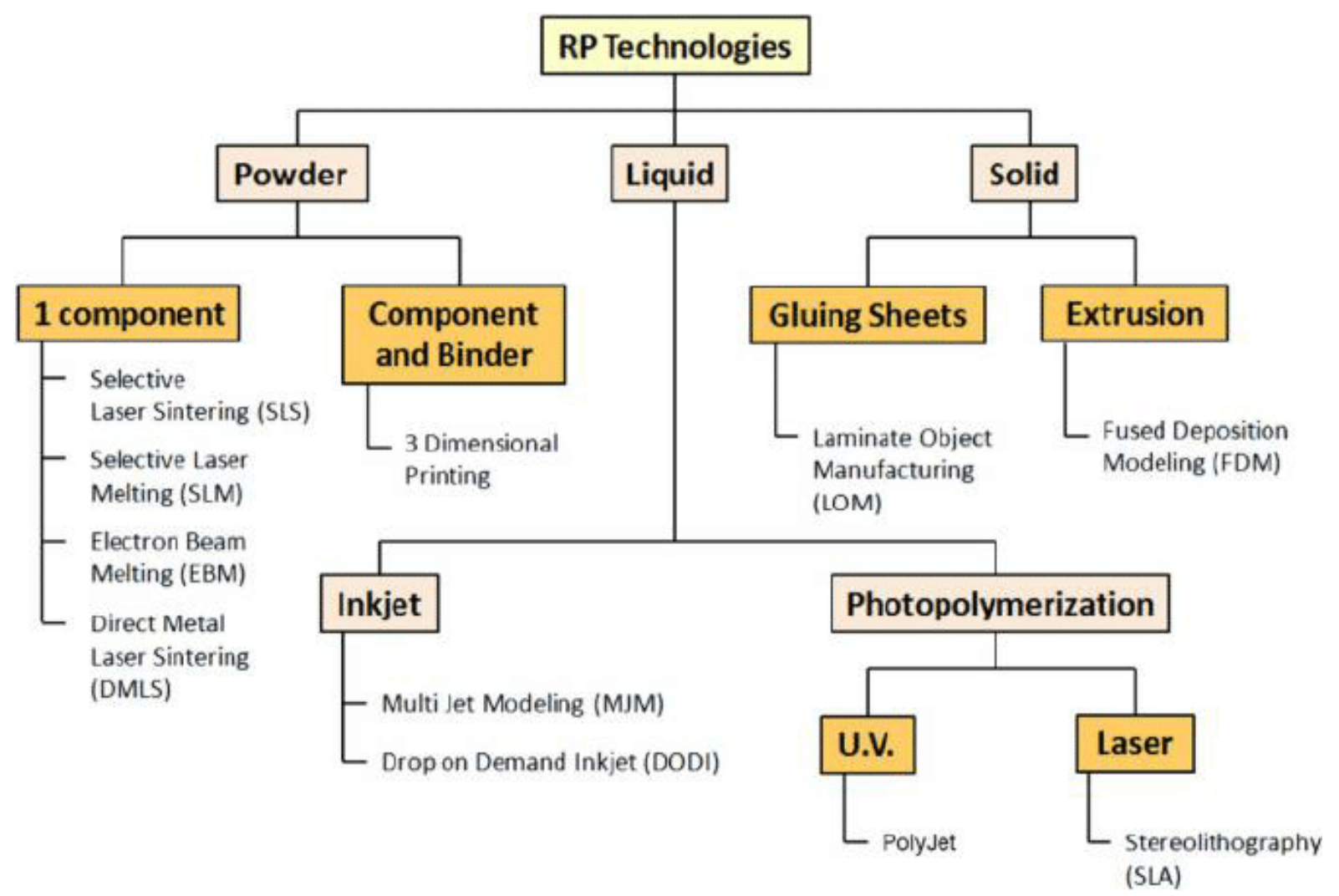

Sintering, melting, fusing or manufacturing objects from various polymerization processes are usually materials: polymers, composites, metals used for "joining" each new and alloys with dense structure and predetermined layer by this edgewise predetermined surface roughness. technology. Thus it paves way for 
Although the Rapid Prototyping has vast number of applications pertaining to Medical, Dental and Bio Medical Engineering, this article tends to narrate only the most widely applied RP techniques in Prosthodontics. It briefly reviews the present technological advancements pertaining to prosthetics. The most extensively used RP technologies in Prosthodontics are Stereolithography (SLA), Fused Deposition Modeling (FDM), Selective Laser Sintering (SLS), Selective Laser Melting (SLM) and Ink-Jet-based Printing $(\text { IJP })^{16,17,18}$.
With advancing options in the 3D printers manufacturing, 3D printing or 3D bioprinting is also being explored for Dentistry avenues. Material research and its upgradation have led to the application of less used RP technique such as Laminated Object Manufacturing (LOM) and Solid Ground Curing (SGC) in the field of Prosthodontics.

Since its inception into the bio medical engineering field in 1988, more than 30 different RP techniques have emerged and been commercialized.

\section{STEREOLITHOGRAPHY:}

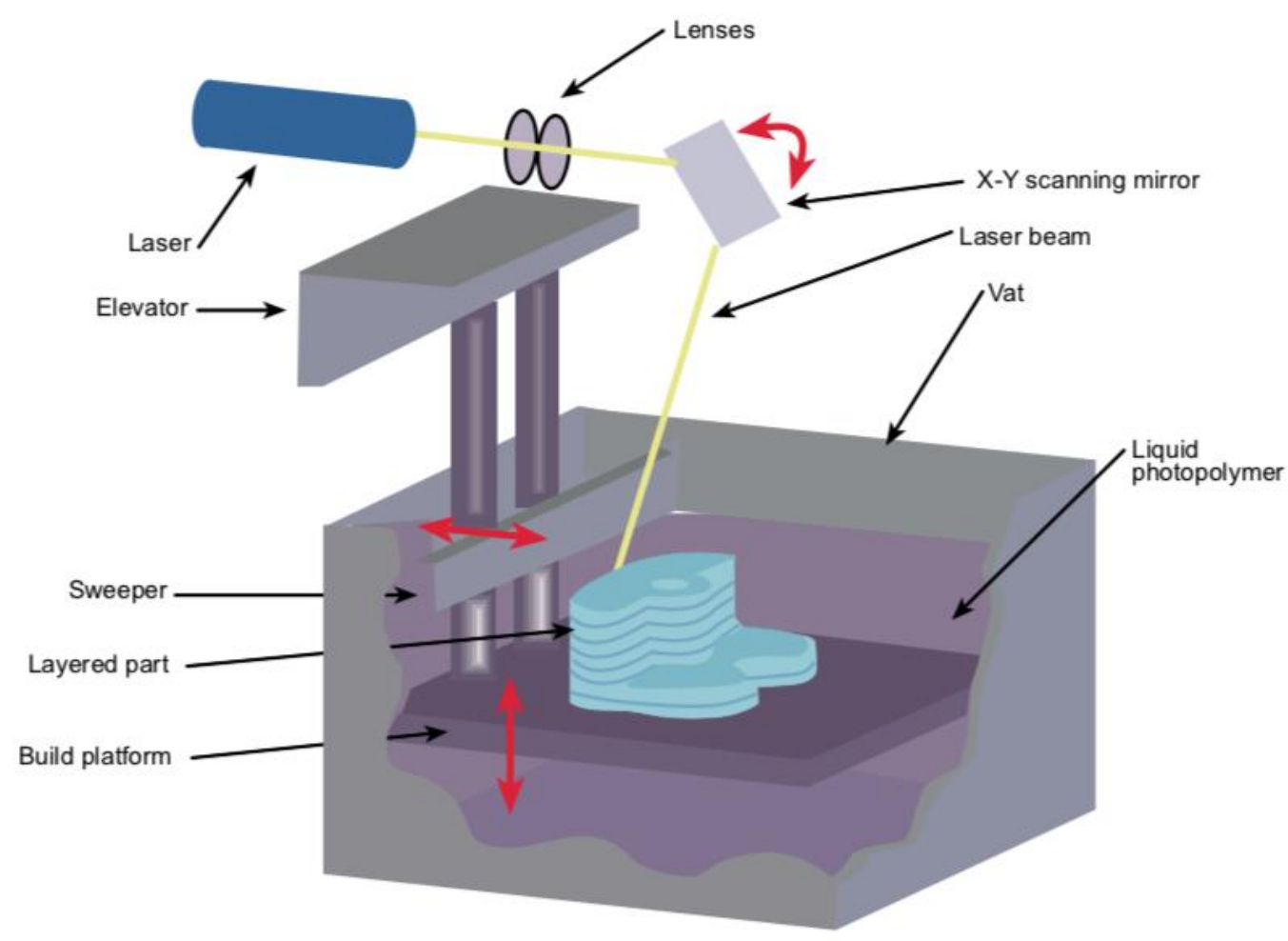

Figure $4^{64}$ : Stereolithography (SLA)

This earliest RP technique was invented and patented by Charles Hull in $1986^{9,10,11,12,13,14}$. The system consists of a bath of photosensitive liquid resin, a model-building platform, and computercontrolled ultraviolet (UV) laser laser beam for curing the resin. The input to the machine/system is fed in the form of 3 dimensional CAD model. The laser beam solidifies the uppermost layer of the photopolymer as per STL file. The resin is cured layer-by-layer beginning from the bottom of the model and building up. As the resin gets exposed to the UV light, it gets cured and hardened. After a layer of resin is cured, the resin platform is lowered by a small known distance. The process continues until the 
finished product is obtained. The support structure is designed along with the final product in CAD model so that the structure is stable. Almost three fourth of the total polymerization is completed in the device's container and the remaining one fourth is completed by means of a conventional UV curing unit.

Applied in the fabrication of surgical templates for oral and extraoral implant placement and preprosthetic surgery ${ }^{15,16,17}$, provisional crowns and bridges $^{18}$, removable partial ${ }^{19}$ and complete dentures $20,21,28$, occlusal splints 22,29 , fabrication of facial prosthesis patterns ${ }^{24,25}$, burnout resin patterns ${ }^{23}$ and cast patterns ${ }^{27}$, custom trays,

SLA technique was later modified by application of digital light projector, known as digital light processing (DLP). After finishing the first layer, the platform raises a short distance from the liquid surface and curing procedure reruns. It thus enables structures to be built from the top of the building platform. Since the structure is lifted by the platform after every layer, the resin required is significantly reduced. ${ }^{26}$

The biggest difference between SLA and DLP is in the formation of these layers. While SLA printers would form the layers point by point, DLP printers form a whole layer at once therby reducing the printing time exponentially. These printers also provide highly accurate results (40-100 $\mu \mathrm{m})$

The favourable factors of SLA are their ability to create complex shapes with internal architecture and the uncomplicated removal of unpolymerized resin.

The main drawback of SLA is the dearth of biocompatible resins possessing features compatible for SLA processing.
Added constraint being the use of photoinitiators and radicals which can be cytotoxic along with the entrapment of unreacted monomer and residual photoinitiator. Photopolymerized resins used has poor mechanical properties, making it difficult to apply in hard tissue engineering. Finally, temporary support structures incorporated into the CAD model to fabricate unsupported features may be difficult to remove.

With the current overtures in the Materials field and advances in the Machining Technology, investing flasks has been fabricated for Complete dentures. This might overcome the long waiting time and multitude appointments necessary especially a boon to limited mouth opening patients and hyperactive gag reflex patients

Another notable advancement is the Micro SLA technique A microstereolithography (m-SLA) system ${ }^{30,31}$ which is an additive manufacturing technology, providing micrometer-scale resolution required for dentistry.

\section{SELECTIVE LASER SINTERING (SLS):}

Discovered and advanced in the middle of 1980 s by Dr.Carl Deckard and Dr.Joe Beaman ${ }^{32,33}$. This is an Indirect layer manufacturing process that allows the generation of $3 \mathrm{D}$ complex pieces by solidifying the successive layers of the material over one another by partial melting process, using the thermal energy provided by a focused high power (CO2 laser) laser beam. With a beam deviation system (Galvano mirrors), scanning of each layer is done corresponding to the cross section calculated from the CAD model. It uses a roller to spread the powdered material on the surface of a build cylinder, which then moves down just one layer thickness to give required space to the new layer of powder. The surface of this 
tightly compacted powder is exposed to laser beam, resulting in the fusion of the powder particles and solid model formation. The process is repeated until completion of the construction. The powder substrate itself forms the supporting structure, hence does not require any other support structures

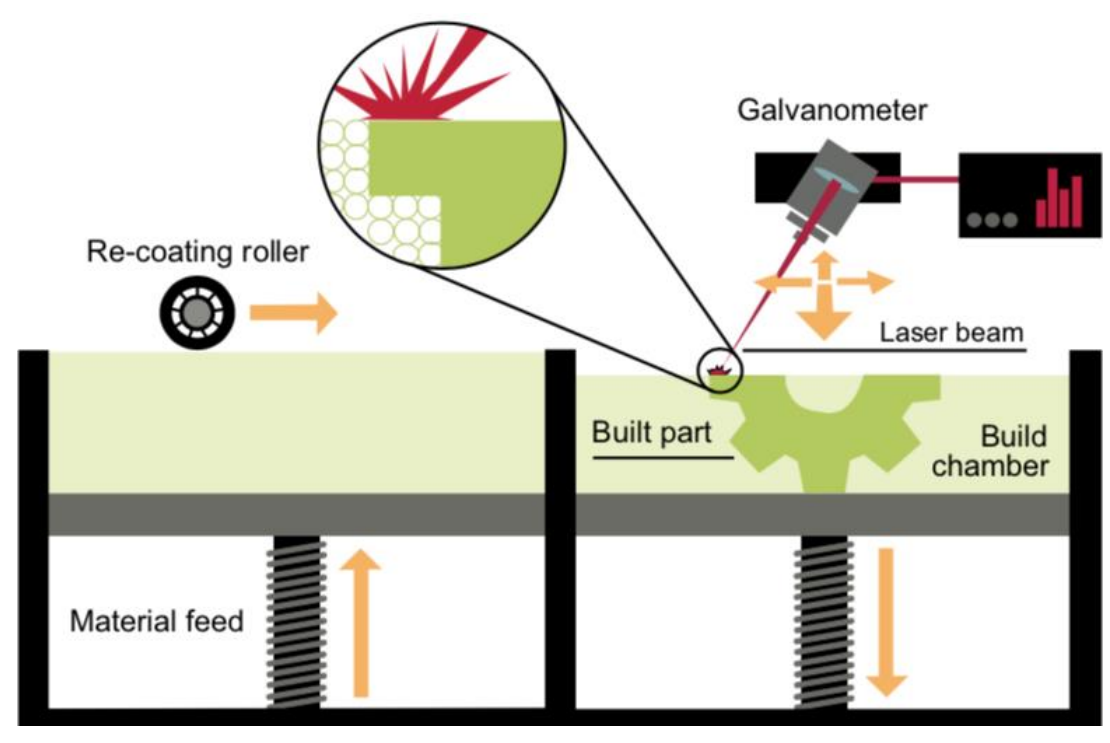

Figure $5^{65}$ : Selective Laser Sintering

SLS technique benefits prosthodontics profundly as thermoplastic materials such as nylon composite, investment casting wax, metallic materials, ceramics and thermoplastic composites can be used in this method. ${ }^{34}$

SLS is a complex thermo - physical process which melts the powder Partially or Fully to form the final structures ${ }^{35,36}$ using different binding mechanisms. A deviation of this SLS process is Selective Laser Melting (SLM), which is a direct method where in the powder particles are Fully melted to construct the desired structure

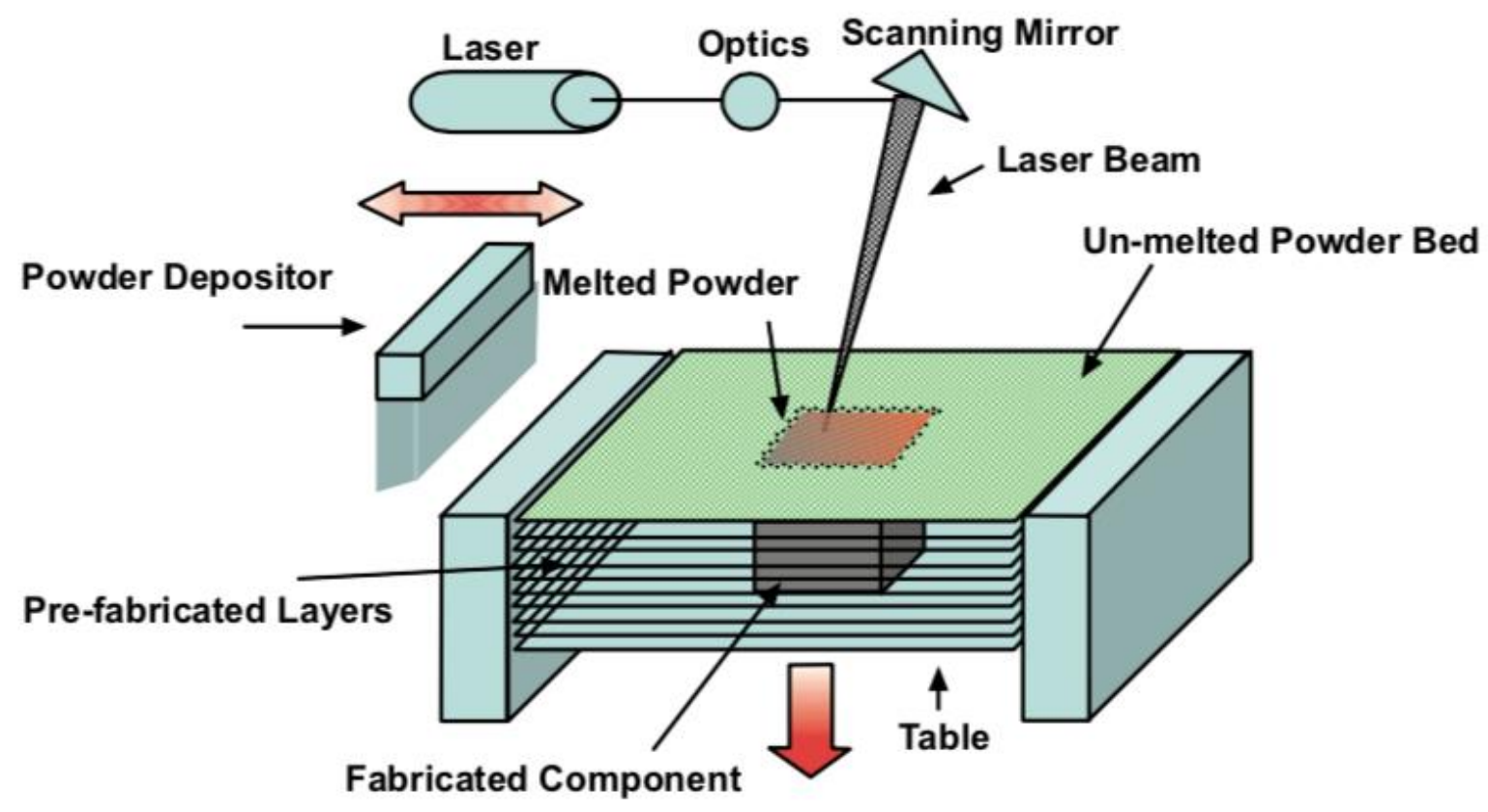

Figure $6^{66}$ : Selective Laser Melting 
In 1995, Selective Laser Melting (SLM) technology for the production of components made of metallic materials (Realizer, 2012) was developed. In 1999, the world's first SLM machine for metals at the research centre in Karlsruhe ${ }^{36,37}$ was introduced.

Direct metal laser sintering (DMLS) is an additive metal fabrication technology developed by EOS from Germany (EOS, 2010a). ${ }^{38}$

The huge advantage is that it produces prosthesis with higher density which assures the rigidity of the framework. Hence it is currently being employed for complex full mouth rehabilitation and Extra oral implant restorations. Marked roughness and partially melted powder on the surface of these copings enhances the mechanical as well as the chemical adhesion of the porcelain to the alloys. Further, this technique gives an efficient and quick strategy to carefully design and make biocompatible metal systems for complex dental prosthesis.

The downfall of this technique being not adequate for use with Polymers and Ceramics. But since studies are being conducted to effectively use this technique for the fabrication of prostheses using Ceramics and Zirconia ${ }^{39}$

\section{FUSED DEPOSITION MODELING (FDM):}

Also known as Fused Filament Fabrication (FFF) Or Extrusion Printing

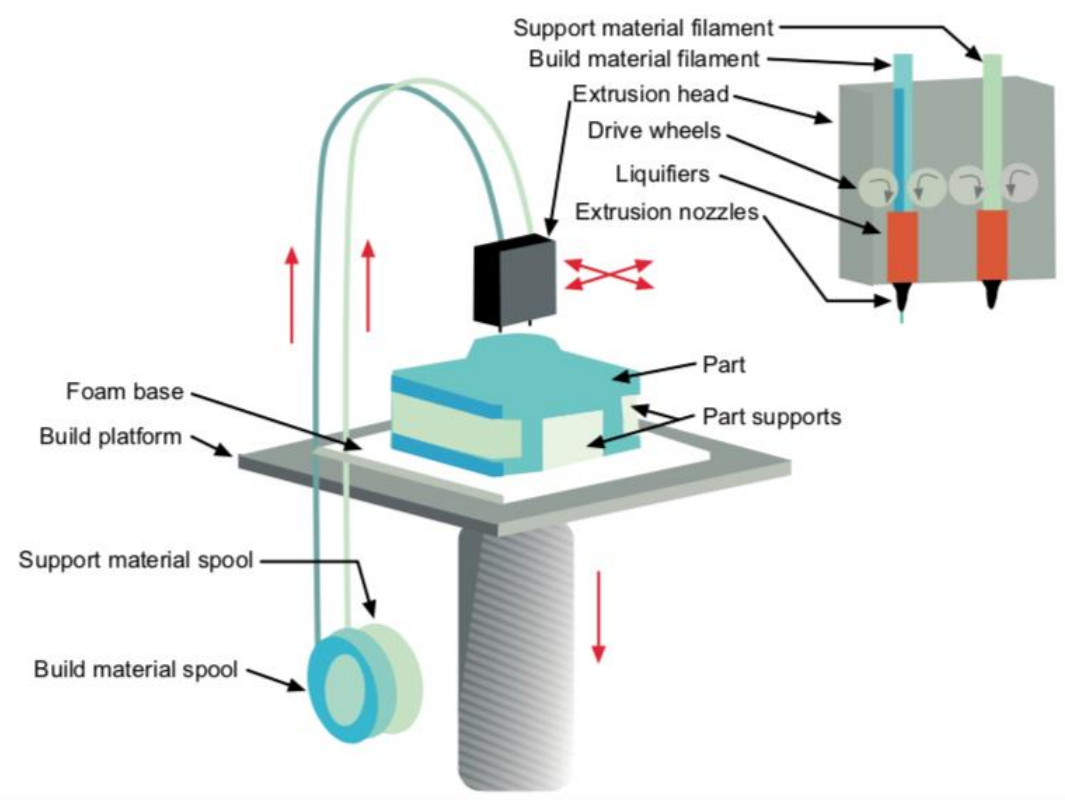

Figure $7^{67}$ : Fused Deposition Modeling

Developed by Schott Crump, 1989, at the company Stratasys, ${ }^{41,42}$ Inc. FDM technique necessitates extrusion of thermoplastic polymer filament material into the temperature controlled extrusion nozzle head, consequently heating it to a semiliquid state. The nozzle head's movement is also computer controlled enabling the material into place with IJDRR: https://escipub.com/international-journal-of-dental-research-and-reviews/ precision. The model is built by layer by layer as the material after being ejected from the nozzle solidifies within $0.1 \mathrm{~s}$ and bonds to the preceding solidified layer. The temperature of entire system is held just below the melting point of the proposed material. 
Present fused deposition modelling (FDM) technologies deposit material as flat layers resulting in a "stair-case" effect on non-linear surfaces and impairs the strength of the models between the laminated layers. To overcome this, Curved FDM method ${ }^{44}$ was introduced wherein materials are deposited as curved layers following the shape of the part, effectively eliminating the staircase effect and thereby fabricating parts having parallel strength distribution of the entire surface. Initially, support material is deposited as conventional flat layers and later build material is deposited over this support structure along their curves.

It is advantageous being cost effective and with no need for chemical post processing. Due to its wide-range of operating temperature, user friendly control system, and huge number of commercial platforms, FDM is furthering into the field of dentistry as one promising technology. Diverse kind of biodegradable materials used in the process FDM printers can accommodate more than one print head and therefore can print multiple types of materials at a single time.
But the major pitfalls like low resolution with limited accuracy, Lack of surface smoothness, Longer working time and difficulty in removing the external support are to be researched further for its wide application in dentistry.

FDM is applied in the fabrication of customized patient-specific medical devices, such as implants, prostheses, anatomical models, and surgical guides.

Up until the recent times, in the dental application of RP, only the metal powders and resin materials has been reported, there were no literatures pertaining to the use of using Polylactic acid (PLA) material for printing a denture pattern ${ }^{42,43}$. The expediency of a novel fabrication method based on $\mathrm{ZrSiO}_{4}$ glass composite in dental prosthesis applications, such as crowns, copings, bridges, and dentures has been researched by Cunico et $\mathrm{al}^{45}$ and concluded the possibility of FDM with proper holding temperature.

Also the production of a 3D-printed denture flask ${ }^{46}$,using conventional complete denture materials, presents an egressing alternative to the digital fabrication of dentures using this FDM technique.

\section{INKJET BASED SYSTEM 3 DP:}

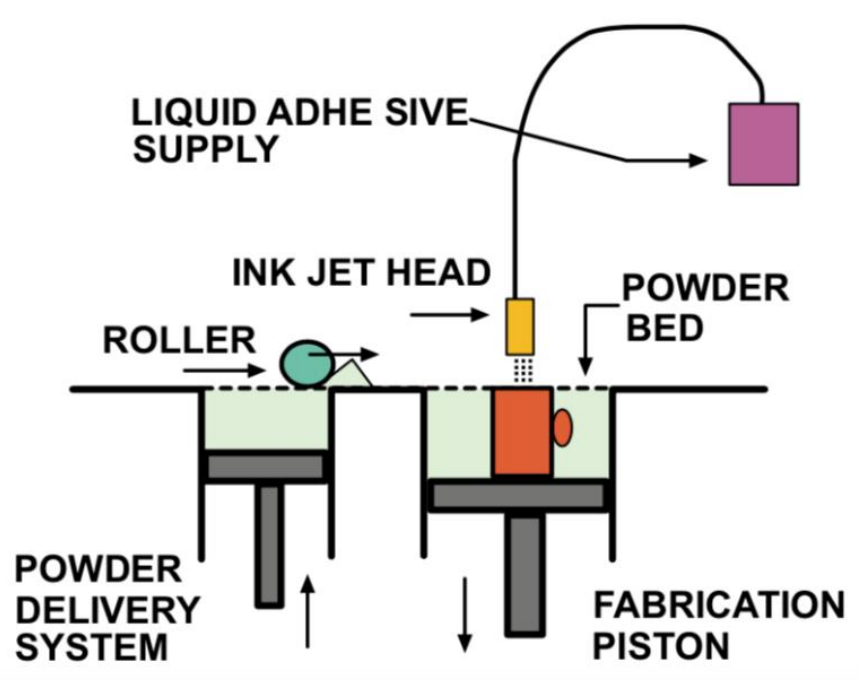

Figure $8^{68}: 3 D$ Inkjet Printing 
Three-Dimensional Printing (3DP), invented at the Massachusetts Institute of Technology, is based on the ability to produce 3D structures in a powder layer with an ink-jet liquid solvent solution

In 1989. Emanuel M. Sachs and his team, at Massachusetts Inst. Technology developed Inkjet printing which is a noncontact reprographic technique ${ }^{47,48}$. Developed at almost the same period as FDM, this process is similar to SLS but replacing the technique of fusing materials with laser or electron beam by selectively dropping the binder liquid onto the powder bed. The system consists of a piston that moves upward incrementally, enabling the dispensing of measured quantity of powder from a supply chamber. A roller distributes and compresses the powder at the top of the fabrication chamber. Ensuing deposition of a liquid adhesive in a 2D pattern onto the layer of the powder from multichannel jetting head. Subsequently the material solidifies by adhesion. As a layer is solidified, the piston that supports the powder bed and the part lowers paving way for the next powder layer. Progressively, this layer-by-layer technique continues till the prototype is completely built up. Water, phosphoric acid, citric acid, PVA are few of the commonly used binding materials for inkjet 3D printing 49,50,51,52. These printers are accurate in the deposition of the binder liquid coupled with speed.

Advantages of Inkjet Printing are ability to print multiple monomers at the same time (i.e., multimaterial printing) with extremely fine resolution and surface finish $^{54,55}$

The drawbacks being longer time duration for overall printing and Limited options for material selection

Helps to produce direct wax patterns, Cost efficient production of all-ceramic dental restorations at high accuracy.

\section{POLYJET PRINTING:}

Comparably new addition to the field of RP and similar to inkjet printing, in this process layers of different photopolymer resin materials can be jetted on to the building platform and simultaneously cured using UV light source. This technology thus enables the possibility of fabricating complex multi-material objects.

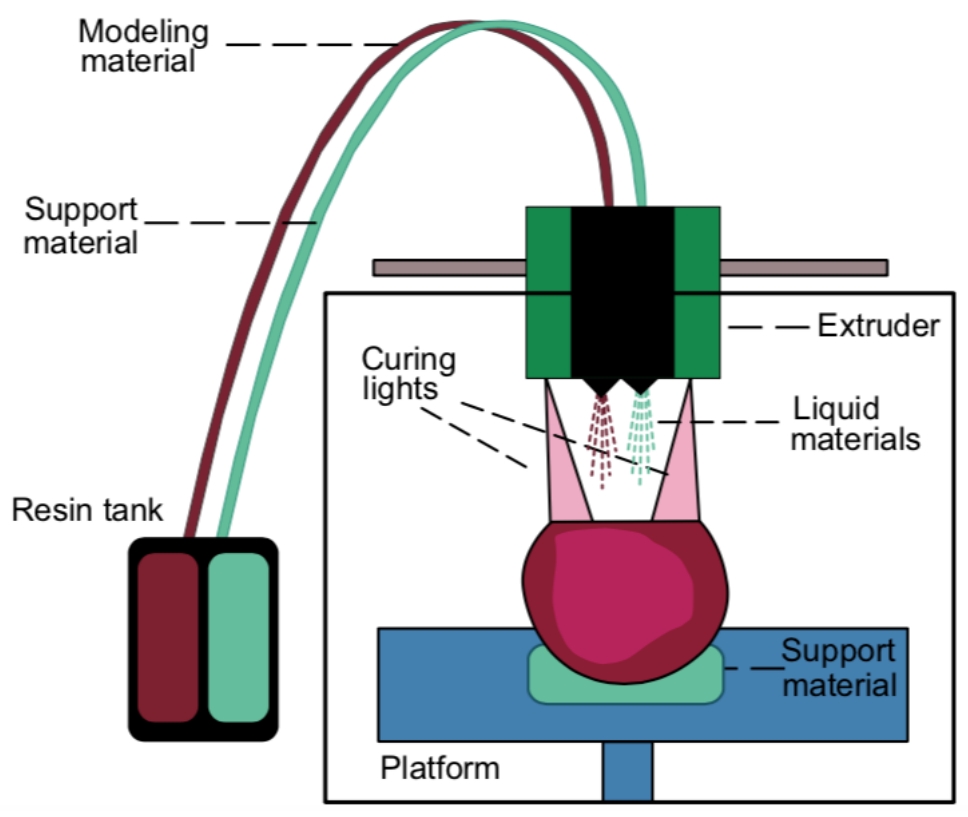

Figure $9^{69}$ : Polyjet Printing 
Polyjet is being extensively used in the medical field to produce complex anatomical models for surgical planning and pre-operative simulations. With this trendsetting technology, high resolution objects with varied modular strengths and high dimensional accuracy can be 3D printed. As the UV source is adjacent to the jetting nozzle, the resin is cured
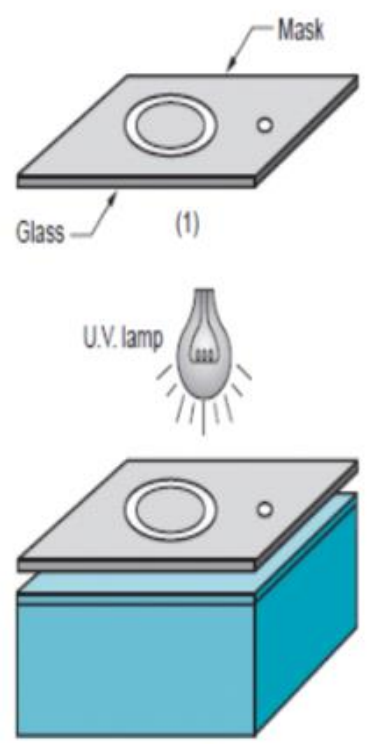

(3)

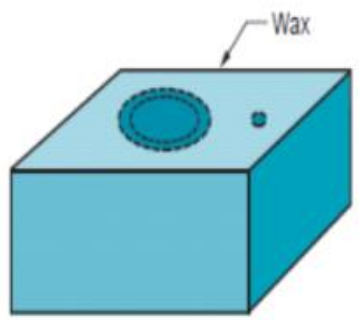

(5) instantaneously and the post-processing of the constructed model is eliminated ${ }^{53}$.

Currently, the inkjet technology is combined with SLA, to create a new generation of $3 \mathrm{D}$ printing machines which are comparatively smaller and less expensive having reduced printing times ${ }^{56}$.

\section{SOLID GROUND CURING (SGC):}

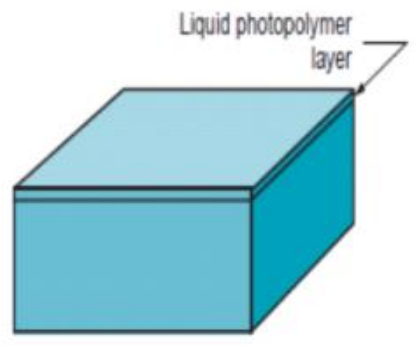

(2)

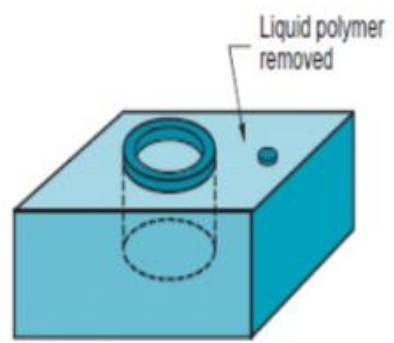

(4)

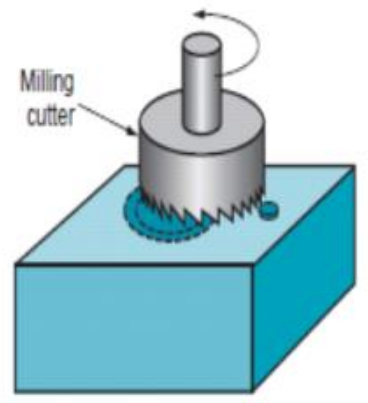

(6)

Figure $10^{70}$ : Solid Ground Curing

1.Mask preparation 2. Liquid photopolymer layer application 3. Positioning mask and exposing the layers 4. Removal of uncured polymer of the surface 5 . Wax filling 6 . Milling the block for flatness and thickness

Solid Ground Curing or Solder Process was invented and developed by Cubital Inc, Israel ${ }^{57,58}$. This technique allows the curing and solidification of a photomask of a section of the model over a photosensitive fluid. Once the preceding layer is cured, the excess liquid resin is vacummed up and a layer of wax is spray deposited in its place to act as supporting structure. The surface layer is milled flat and then the process is repeated to build the next layer. Finally 
the wax is removed in a solvent bath after the construction is complete. This technique can build multiple parts concurrently due to the high throughput achieved by hardening each layer of photosensitive resin at the same time ${ }^{59,60}$.

The advantages of SGC are its high structural strength and stability with minimum shrinkage

The limitation of this budding technology is its expensive, complex setup requiring huge space and generates waste byproducts.

This technology is applied in dentistry for Wax pattern fabrication- PFM crowns, pressed ceramic crowns, RPD frameworks, Maxillofacial prosthesis, Mould for metal casting, Mould for complete denture, Direct metal prosthesis fabrication.

\section{CONCLUSION:}

To consolidate this review, it can be stated that digitalization of the biomedical field has created a tremendous momentum in the manufacturing of prosthesis in limited time and greater accuracy. With the upgradation in 3D modelling software and mechanics of the printing machine, contemporaneous advancement in the dimensional precision, speed and attuning of a $3 \mathrm{D}$ printed prosthesis has been achieved. Hence these RP technology are extensively applied clinically for the fabrication of patientspecific implants and prostheses. Prosthodontics being a blend of Artistry and Technology, this upcoming technology reduces the reliance on human variables and possibly overcome the limitations of conventional methods requiring considerable human intervention.
Handling of resin or wax materials exhibiting inherent processing shrinkage/expansion can be eliminated and the prosthesis closely resembling the missing anatomical structure can be reproduced. Advances in dental science, dental materials and newer manufacturing technologies, and aggregation of all plays an inclination towards the furtherance of RP in dentistry. This technology is becoming portable and more pervasive due to the progressing researches in both the engineering and biomedical fields.

The impediment of the RP technology consists of complicated machinery and dependency on human expertise to operate the machinery during production coupled with the huge cost of the equipments. Acclimatising with these new tools and machinery to employ them in a germane manner and to evaluate these current innovations is necessary for the technicians and the clinicians also.

The shortcomings such as handling skill of the machinery, materials available must be appropriately revolutionized. As Rapid Prototyping Technology forays into the future, it will become the norm of the Prosthetic rehabilitation and be imperative to the field of dentistry.

CONFLICT OF INTEREST: The author have no conflicts of interest relevant to this article.

\section{REFERENCES:}

1. Mayo Cohen, A. "Print future of dentistry: 3-D printing". Dental Health Magazine. Free Dentistry information and dental News for Patients.26 Jan 2010. Web.3 May 2010

2. J. Winder and R. Bibb, "Medical Rapid Prototyping Technologies: State of the Art and Current 
Limitations for Application in Oral and Maxillofacial Surgery," Journal of Oral and Maxillofacial Surgery, Vol. 63, No. 7, 2005, pp. $1006-$ 1015

3. Torabi K, Farjood E, Hamedani S. Rapid prototyping technologies and their applications in prosthodontics, a review of literature. Journal of Dentistry. 2015;16(1):1

4. Andonović V, Vrtanoski G. Growing rapid prototyping as a technology in dental medicine. Mech Eng Sci J. 2010;29(1):31-9

5. Quadri S, Kapoor B, Singh G, Tewari RK. Rapid prototyping: An innovative technique in dentistry. Journal of Oral Research and Review. 2017;9(2):96

6. Wohlers T, Gornet T. History of additive manufacturing. Wohlers Report: Additive Manufacturing and 3D Printing State of the Industry Annual Worldwide Progress Report. 2011

7. Van Noort R. The future of dental devices is digital, Dent Mater. 2012; 28:3-12.

8. Dovbish VM, Zabednov PV, Zlenko MA. Additivnie tehnologii I izdelia iz metala, $57 \mathrm{p}$

9. Hull CW. 1986. Apparatus for production of three-dimensional objects by stereolithography. https://www.lens.org/lens/ patent/ 022-138-245-291-118.

10. Oberoi $G$, Nitsch $S$, Edelmayer $M$, Janjić K, Müller AS, Agis H. 3D Printing-Encompassing the Facets of Dentistry. Front Bioeng Biotechnol. 2018 Nov 22;6:172. doi: $\quad 10.3389 /$ fbioe.2018.00172. PMID: 30525032; PMCID: PMC6262086.

11. Abduo J, Lyons K, Bennamoun M. Trends in computer-aided IJDRR: https://escipub.com/international-journal-of-dental-research-and-reviews/ manufacturing in prosthodontics: a review of the available streams. Int $J$ Dent. 2014;2014:783948. doi: 10.1155/2014/783948. Epub 2014 Apr 8. PMID: 24817888; PMCID: PMC4000974.

12. Chee Kai Chua, Kah Fai Leong, Chu Sing Lim. Rapid Prototyping: Principles And Applications (3rd Edition) Pg 1 - 252010

13. Chua, C.K., "Three-dimensional rapid prototyping technologies and key development areas," Computing and Control Engineering Journal 5(4) (1994): 200-206.

14. Chua, C.K., "Solid modeling- A state-of-the-art report," Manufacturing Equipment News (September 1987): 33-34.

15. Nayar $S$, Bhuminathan $S$, Bhat WM. Rapid prototyping and stereolithography in dentistry. J Pharm Bioall Sci 2015;7, Suppl S1:216-9.

16. Islas M., Noyola M., Martínez R., Pozos A., Garrocho A., 2015: Fundamentals of Stereolithography, an Useful Tool for Diagnosis in Dentistry.ODOVTOS-Int. J. Dental Sc., 17-2 (May-August): 15-21

17. Hossein Kheirollah, Farid Abbaszadeh .Application of rapid prototyping technology in dentistry. Int. J. Rapid Manufacturing, Vol. 2, Nos. 1/2, 2011

18. Iveta Katreva1, Tsanka Dikova1, Tsvetan Tonchev 3d Printing - An Alternative Of Conventional Crown Fabrication: A Case Report J of IMAB. 2018 Apr-Jun;24(2)

19. Sun YC, Lu 'PJ, Wang Y: Study on CAD\&RP for removable complete denture. Comput Method Programs Biomed 2009; 93:266-272. 
20. M. Inokoshi, M. Kanazawa, and S. Minakuchi, "Evaluation of a complete denture trial method applying rapid prototyping," Dental Materials Journal, vol. 31, no. 1, pp. 40-46, 2012

21. Kanazawa $M$, Inokoshi $M$, Minakuchi S, Ohbayashi N. Trial of a CAD/CAM system for fabricating complete dentures. Dent Mater J 2011; 30: 93-96

22. Hecht, J., The Laser Guidebook, 2nd edition, McGraw Hill, New York, 1992

23. Oberoi G, Nitsch S, Edelmayer M, Janjic K, Müller AS and Agis $H$ (2018) 3D Printing-Encompassing the Facets of Dentistry. Front. Bioeng. Biotechnol. 6:172

24. Z. Feng, Y. Dong, Y. Zhao et al., "Computer-assisted technique for the design and manufacture of realistic facial prostheses," British Journal of Oral and Maxillofacial Surgery, vol. 48, no. 2, pp. 105109, 2010

25. Y. Bi, S. Wu, Y. Zhao, and S. Bai, "A new method for fabricating orbital prosthesis with a CAD/CAM negative mold,"The Journal of Prosthetic Dentistry, vol. 110, no. 5, pp. 399-408, 2013

26. 3D printing in Dentistry Technology Overview and Options. https://instituteofdigitaldentistry.co $\mathrm{m} / 3 d$-printing/3d-printing-indentistry-technology-overview/

27. Hezhen Li, Lu Song, Jialin Sun, Jing Ma \& Zhijian Shen (2019) Dental ceramic prostheses by stereolithography-based additive manufacturing: potentials and challenges, Advances in Applied Ceramics, 118:1-2,30-36

28. Chang, C.C., Lee, M.Y. \& Wang, S.H. Digital denture manufacturing-An integrated IJDRR: https://escipub.com/international-journal-of-dental-research-and-reviews/ technologies of abrasive computer tomography, CNC machining and rapid prototyping. Int $\mathrm{J}$ Adv Manuf Technol 31, 41-49 (2006). https://doi.org/10.1007/s00170005-0181-z

29. M. Salmi, K. S. Paloheimo, J. Tuomi et al., "A digital process for additive manufacturing of occlusal splints: a clinical pilot study," Journal of the Royal Society, Interface/the Royal Society, vol. 10, no. 84, pp. 1-6, 2013.

30. Dong-Yeon Kim, II-Do Jeong, JiHwan Kim, Hae-Young Kim, Woong-Chul Kim. Reproducibility of different coping arrangements fabricated by dental microstereolithography: Evaluation of marginal and internal gaps in metal copings Journal of Dental sciences (2018)13 220-225

31. Martinez Pellitoro et al. Analysis of Influence factors on part quality in micro SLA technology. Manufacturing Engineering Society International Conference 2017, MESIC 2017, 28-30 June 2017, Vigo (Pontevedra), Spain

32. J.-P. Kruth, B. Vandenbroucke, J. Van Vaerenbergh, Naert. Rapid Manufacturing of Dental Prostheses by means of Selective Laser Sintering/Melting. Proceedings of the 2nd International Conference on Advanced Research in Virtual and Rapid Prototyping, Leiria, Portugal, 28th Sept - 1st Oct 2005.

33. Deckard C, Beaman J. Process and control issues in selective laser sintering. ASME Prod Eng Div PED 1988; 33: 191- 197

34. Bibb R, Eggbeer D, Williams R. Rapid manufacture of removable partial denture frameworks. Rapid Prototyping J 2006; 12: 95-99. 
35. Moraru, Edgar \& Dontu, Octavian \& Alexandru, Petre \& Vaireanu, D \& Constantinescu, F \& Besnea, D. (2020). Some technological particularities on the execution of dental prostheses realized by selective laser deposition. Journal of Optoelectronics and Advanced Materials. 20. 208-213.

36. Udroiu, Razvan. (2012). Powder bed additive manufacturing systems and its applications. Academic Journal of Manufacturing Engineering 1583-7904. 10. 122129.

37. A Nehir Özden and Mohammed Abujalala. "Rapid Prototyping Technologies in Prosthetic Dentistry". EC Dental Science 14.5 (2017): 217-224

38. Razvan Udroiu Powder Bed Additive Manufacturing Systems And Its Applications Academic Journal Of Manufacturing Engineering, Vol. 10, Issue 4/2012 122- 129

39. Upadhyaya, Viram. (2018). Additive Prototyping in Dentistry3D Printing and Selective Laser Sintering. Open Access Journal of Dental Sciences. 3 . 10.23880/OAJDS-16000166.

40. Dzhendo Dzhendov, Tsanka Dikova, Application Of Selective Laser Melting In Manufacturing Of Fixed Dental Prostheses J of IMAB. 2016, vol. 22, issue 4

41. Deng $\mathrm{K}$, Chen $\mathrm{H}$, Zhao $\mathrm{Y}$, Zhou $\mathrm{Y}$, Wang $Y$, Sun $Y$ (2018) Evaluation of adaptation of the polylactic acid pattern of maxillary complete dentures fabricated by fused deposition modelling technology: A pilot study. PLoS ONE 13(8): e0201777

42. Danial Khorsandi., et al. "Fused Deposition Modeling and IJDRR: https://escipub.com/international-journal-of-dental-research-and-reviews/
Stereolithography 3D Bioprinting in Dental Science". EC Dental Science 18.1 (2019): 110-115.

43. Lee D, Lee SY, Kim H, Park C. A Hybrid Dental Model Concept Utilizing Fused Deposition Modeling and Digital Light Processing 3D Printing. Int $J$ Prosthodont. 2020 Mar/Apr;33(2):229-231. doi: 10.11607/ijp.6534. PMID: 32069349.

44. S. Singamneni, 0. Diegel, B. Huang, I. Gibson, And R. Chowdhury. Curved-Layer Fused Deposition Modelling Journal for New Generation Sciences: Volume 8 Number 2 95- 107

45. Cunico, Marlon. "Investigation of Ceramic Dental Prostheses Based on ZrSiO4-Glass Composites Fabricated by Indirect Additive Manufacturing." International Journal of Bioprinting [Online], 7.1 (2021): $n$. pag. Web. 21 Jan. 2021

46. Kim, H., Lee, D., Young Lee, S., Yang, H., Park, S.-W., Lim, H.-P., Park, C. (2019). Denture flask fabrication using fused deposition modeling three-dimensional printing. Journal of Prosthodontic Research. doi:10.1016/j.jpor.2019. 07.001

47. Thomas Boland, Tao Xu, Brook Damon and Xiaofeng Cui. Biotechnol. Application of inkjet printing to tissue engineering $\mathrm{J}$. 2006, 1, 910-917.

48. Sachs E, Cima M, Cornie J. 1990. Three-dimensional printing: rapid tooling and prototypes directly from a CAD model. CIRP Annals 39:201-204

49. Meteyer S, Xu X, Perry N, Zhao YF. 2014. Energy and material flow analysis of binder-jetting additive 
manufacturing

processes.

Procedia CIRP 15:19-25

50. Cima MJ, Sachs E, Cima LG, Yoo $J$, Khanuja S, Borland SW., "Computer derived microstructures by 3D printing: bio-and structural materials", Solid Free form Fabr. Symp. Proc. DTIC Document, Pages 181-190, 1994.

51. Xiong, Y., Chao Q., Jian S., "Fabrication of porous titanium implants by three-dimensional printing and sintering at different temperatures." Dental materials journal, Vol. 31, Issue 5, Pages 815-820, 2018.

52. Liao W, Xu L, Wangrao K, Du Y, Xiong Q, Yao Y. 2019. Threedimensional printing with biomaterials in craniofacial and dental tissue engineering. PeerJ $7: e 7271$

53. Cima MJ, Sachs E, Cima LG, Yoo J, Khanuja S, Borland SW., "Computer derived microstructures by 3D printing: bio-and structural materials", Solid Free form Fabr. Symp. Proc. DTIC Document, Pages 181-190, 1994.

54. Xiong, Y., Chao Q., Jian S., "Fabrication of porous titanium implants by three-dimensional printing and sintering at different temperatures." Dental materials journal, Vol. 31, Issue 5, Pages 815-820, 2018.

55. A validation study of reconstructed rapid prototyping models produced by two technologies Christian Andreas Dietricha ; Andreas Enderb ; Stefan Baumgartnerc ; Albert Mehld Angle Orthodontist, Vol 87, No 5, 2017

56. Pratik Bhatnagar, Jaspreet Kaur, Pooja Arora, Vipin Arora. International Journal of Life Sciences.2014;3(2):50-53
57. American institute of Architects. Architectural graphic standard. $11^{\text {th }}$ ed Hoboken: John wiley and sons 2007

58. Joshi, M.D. (2006) Rapid prototyping technology in maxillofacial prosthodontics: Basics and applications. The Journal of Indian Prosthodontic Society. 6(4): 175-178

59. Jain, N., Pathak, C., Manisha, Kaur, H., Kundra, S., Ritu, \& Kumar, A. (2016). Rapid Protyping: A new chapter in Dentistry International Journal of Oral Care and Research; Oct- Dec 2016;4(4):301-304

60. Kamath $\mathrm{M}$ et al. Rapid Prototyping in Prosthodontics. International Journal of Oral Health and Medical Research | ISSN 2395-7387 January-February 2019 | Vol 5 Issue 5

61. Liwei Lin, Yingfeng Fang, Yuxuan Liao, Gang Chen, Chunxia Gao, Peizhi Zhu.3D Printing and Digital Processing Techniques in Dentistry: A Review of Literature. Adv. Eng. Mater. June 2019, Volume21, Issue6.

62. Sasa T. Zivanovic et al. An Overview of Rapid Prototyping Technologies using Subtractive, Additive and Formative Processes. FME Transactions (2020) 48, 246 253

63. Katreva, Iveta \& Dikova, Tsanka \& Abadzhiev, Metodi \& Tonchev, Tsvetan \& Dzhendov, Dzhendo \& Simov, Maksim \& Angelova, Svetlana \& Pavlova, Diana \& Doychinova, Maya. (2016). 3Dprinting in contemporary prosthodontic treatment. Scripta Scientifica Medicinae Dentalis. 2. 16-20. 10.14748/ssmd.v1i1.1446. 
64. Mouzakis, Dionysios. (2018). Advanced Technologies in Manufacturing 3D-Layered Structures for Defense and Aerospace. 10.5772/intechopen. 74331.

65. https://rapidfab.ricoheurope.com/technologies/selective -laser-sintering/

66. Mumtaz, K. A., Erasenthiran, P., \& Hopkinson, N. (2008). High density selective laser melting of Waspaloy ${ }^{\circledR}$. Journal of Materials Processing Technology, 195(1-3), 77-

87. doi:10.1016/j.jmatprotec.2007. 04.117

67. Ramana, T. \& Subhash, Sagam \& Balakrishna, Sangem. (2019). Modelling and 3D Printing of Crankshaft. International Journal of Trend in Scientific Research and Development. Volume-3. 10391043. 10.31142/ijtsrd23224.

68. https://imieurope.com/inkjetblog/2016/1/19/3d-printing-theonly-way-is-up

69. Groth $\mathrm{CH}$, Kravitz ND, Jones PE, Graham JW, Redmond WR. Threedimensional printing technology. J Clin Orthod. 2014 Aug;48(8):47585.

70. Hashimi, Md.Hira. (2017). Design, Planning, Machining, and Manufacturing Using Rapid Prototyping Technologies in Modern Engineering. International Journal of scientific research and management.

10.18535/ijsrm/v5i1.07. 